\title{
Surgical Management of Abdominal Trauma: Indications and Outcomes in Two Emergency Units with Limited Infrastructure Resources in Yaoundé (Cameroon)
}

\author{
Savom Eric Patrick ${ }^{1,2 *}$, Bang Guy Aristide ${ }^{2,3}$, Biwole Biwole Daniel2,4, Bitang A. Mafok Louis Joss ${ }^{5}$, \\ Bwelle Motto Georges Roger 2,4, Ekani Boukar Mahamat Yannick6, Ngo Nonga Bernadette2,3, \\ Essomba Arthur2,3 \\ ${ }^{1}$ Yaoundé General Hospital, Yaoundé, Cameroon \\ ${ }^{2}$ Faculty of Medicine and Biomedical Sciences, University of Yaoundé I, Yaoundé, Cameroon \\ ${ }^{3}$ Yaoundé Teaching Hospital, Yaoundé, Cameroon \\ ${ }^{4}$ Yaoundé Central Hospital, Yaoundé, Cameroon \\ ${ }^{5}$ Yaoundé Emergency Centre, Yaoundé, Cameroon \\ ${ }^{6}$ Faculty of Health Sciences, University of Buea, Yaoundé, Cameroon \\ Email: *esavom@yahoo.fr, guyaristidebang@yahoo.fr, dbmvoe@gmail.com, ljbitang@yahoo.fr, bwelleg@gmail.com, \\ boukaryoussouf@gmail.com,ngonongab@yahoo.com, artgessomba@gmail.com
}

How to cite this paper: Patrick, S.E., Aristide, B.G., Daniel, B.B., Joss, B.A.M.L., Roger, B.M.G., Yannick, E.B.M., Bernadette, N.N. and Arthur, E. (2021) Surgical Management of Abdominal Trauma: Indications and Outcomes in Two Emergency Units with Limited Infrastructure Resources in Yaoundé (Cameroon). Surgical Science, 12, 339-349. https://doi.org/10.4236/ss.2021.1210035

Received: September 15, 2021

Accepted: October 22, 2021

Published: October 25, 2021

Copyright $\odot 2021$ by author(s) and Scientific Research Publishing Inc. This work is licensed under the Creative Commons Attribution International License (CC BY 4.0).

http://creativecommons.org/licenses/by/4.0/

\section{(c) (i) Open Access}

\begin{abstract}
Introduction: Abdominal trauma is a major public health concern. Their management is controversial and difficult. Operative indications are not codified in all situations. Patients and Methods: This was a descriptive crosssectional study over a period of 5 years, carried out in the surgical emergency department of the Central Hospital of Yaoundé and the Emergency Centre of Yaoundé. We reviewed retrospectively medical records of patients who had laparotomy after abdominal trauma. Results: We collected 115 files. There was a male predominance $(83.47 \%)$ and the average age was 33.8 years. The average time to admission was 12.3 hours and the aetiologies were dominated by road traffic accidents (53\%). Abdominal contusions represented $69.56 \%$ of cases and abdominal wounds $30.44 \%$ of cases. Indications for surgery were hemodynamic instability, evidence of a lesion of a hollow viscus, the presence of evisceration or a gunshot wound, and initial non-operative treatment failure. Postoperative morbidity was $9.56 \%$ and overall mortality was $3.47 \%$. Conclusion: Surgical management of abdominal trauma is frequent in our setting, mainly indicated for hemodynamic instability. Results are good with a low morbi-mortality.
\end{abstract}




\section{Keywords}

Abdominal Trauma, Abdominal Contusion, Abdominal Wound, Surgical Indications, Yaoundé

\section{Introduction}

Abdominal trauma (AT) is lesions produced at the level of the abdominal wall and/or its contents by an external agent. They can be opened, by rupture of the parietal continuity (abdominal wounds), or closed (abdominal contusions), respecting the parietal continuity, and responsible for visceral lesions (full or hollow viscera) which can be life threatening. They are a major public health problem due to their frequency and their consequences, because they have a high mortality rate of up to $25 \%$ to $27 \%$ [1] [2]. While the aetiologies are multifactorial, road traffic accidents (RTA) are the mechanism most often at the origin of these lesions [2] [3] [4] [5] [6]. Their prognosis depends on the severity of abdominal lesions, associated extra-abdominal lesions and treatment' efficiency [7].

In closed AT, hemodynamic state and signs of peritoneal irritation are the key elements of the therapeutic decision. Two approaches are opposed in the management of open AT: systematic laparotomy and selective abstention. The choice of the type of initial management depends on clinical and technical platform available [8].

The management of $\mathrm{AT}$ is therefore complex and must meet certain principles [9] [10]. It requires adequate diagnostic resources and technical platform, which are not always available in some limited settings like our own.

In our country, Ultrasound and CT scans, although more and more frequently used, are not always accessible and/or available in emergency. Furthermore, interventional radiology and laparoscopy are not available in the majority of health structures, including those selected for this study. Thus, in case of failure/ non-indication of conservative treatment of patients with AT, an exploratory laparotomy remains the main management tool in our context. We conducted this study with the aim of determining indications and results of the surgical management of patients with AT surgery in our context.

\section{Patients and Methods}

We conducted a descriptive cross-sectional study in the surgical emergency departments of two university hospitals in Yaoundé, the capital city of Cameroon, a country in Sub-Saharan Africa: the Yaoundé Central Hospital and the Yaoundé Emergencies Centre.

We reviewed the operative and hospitalization's reports of these hospitals to identify all the patients operated for an abdominal trauma over a 5-year period, from January 2015 to December 2019. Their files were then consulted to fulfill 
the data collection form; studied variables were: Patients' demographic, clinical and paraclinical presentation, surgical findings and postoperative 30 days outcomes. Incomplete files and files of patients loss to follow up before the postoperative day $30^{\text {th }}$ were excluded.

Data analysis was performed using Microsoft Office Excel 2016 and SPSS version 20.0 software. Means and standard deviations were calculated for quantitative data and qualitative variables were reported as counts and percentages.

\section{Results}

During the study period, 681 patients were managed for trauma. Among them, 377 had abdominal trauma, representing $55.35 \%$ of all trauma. Two hundred and six patients (54.64\%) were operated and 91 files were excluded (44.17\%).

We thus collected 115 patients, among whom 96 men (83.47\%) and 19 women (16.53\%) with a sex ratio of 5.1. They were aged from 15 to 75 years with an average of $33.8 \pm 11.3$ years. Ninety-five patients $(82.6 \%)$ were under 45 years old. The socio-demographic characteristics of our study population and trauma aetiologies are summarized in Table 1.

The mean time from the trauma to admission was 12.3 hours \pm 11.7 . The transfer was medicalized in $10.43 \%$ of cases. Abdominal contusions represented $69.56 \%$ of cases ( 80 patients) and abdominal wounds in $30.44 \%$ of cases (35 patients). The aetiologies were dominated by RTA in $53 \%$ and assaults in $38.26 \%$ of cases.

All aetiologies combined, hemodynamic instability was noted in 64 patients (55.65\%) and peritoneal irritation in 38 patients (33.04\%). Nine patients (7.82\%) had evisceration (Figure 1). An abdominal ultrasound was performed in $54.78 \%$ of patients and a plain abdominal x-ray in $27.82 \%$ of cases. A CT scan was only obtained in $17.39 \%$ of the injured patients. All patients had a midline laparotomy.

Table 1. Sociodemographic and clinical characteristics.

\begin{tabular}{lcc}
\hline \multicolumn{1}{c}{ Variables } & Number & Percentage \\
\hline Sex & 96 & \\
\multicolumn{1}{c}{ Men } & 19 & 83.47 \\
Women & & 16.53 \\
\hline Age & 26 & \\
$\quad<25$ & 69 & 22.60 \\
$25-45$ & 19 & 60 \\
$45-65$ & 1 & 16.52 \\
$\geq 65$ & & 0.86 \\
\hline Type of trauma & 80 & \\
$\quad$ Abdominal contusion & 35 & 69.56 \\
Abdominal wound & & 30.44 \\
\hline Aetiologies & 61 & \\
$\quad$ RTA & 44 & 53.04 \\
$\quad$ Assaults & 8 & 38.26 \\
$\quad$ Work accidents & 2 & 6.95 \\
$\quad$ Sport accidents & & 1.73 \\
\hline
\end{tabular}




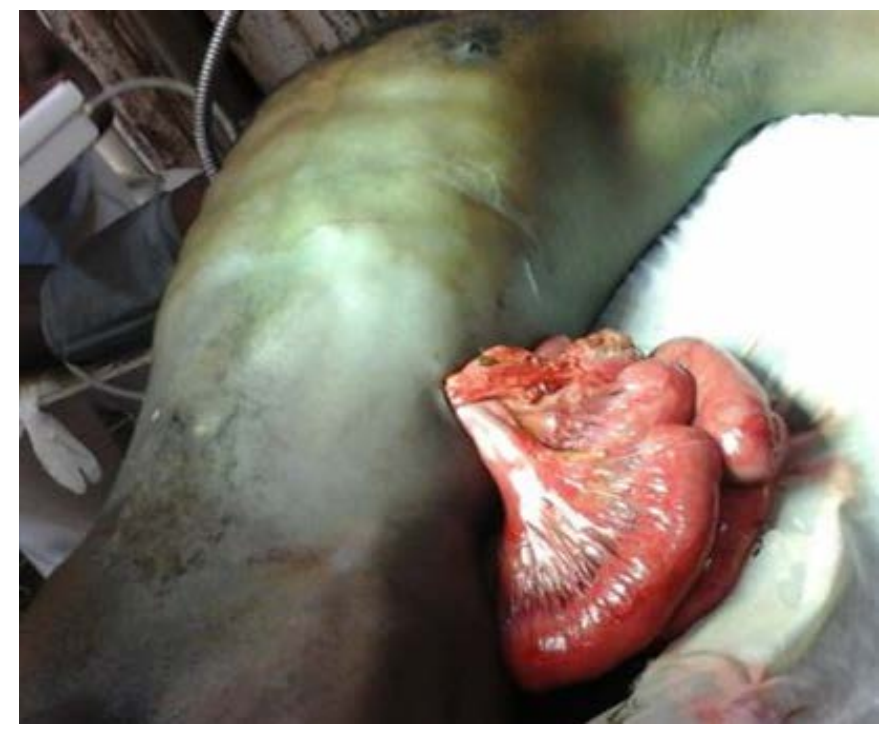

Figure 1. Small bowel and omentum evisceration in a patient presenting a stab wound injury.

The mean hospital stay was 9.7 days \pm 12.3 . The postoperative course was complicated in 11 patients, for a morbidity of $9.56 \%$. Four patients died giving an overall mortality of $3.47 \%$.

In the contusions group $(n=80)$, the aetiologies were dominated by RTA in $73.75 \%$ and assault in $13.75 \%$ of cases. Hemodynamic instability was present in $70 \%$ of cases and peritoneal irritation in $22.5 \%$ of patients. The trauma was isolated in $63.75 \%$ of the patients and was part of a polytrauma in $20 \%$ of the cases. Sixty-three patients $(78.75 \%)$ were operated in emergency and surgical indications were: refractory hemodynamic instability (42 cases, 66.67\%), peritonitis (17 cases, 27\%), pneumoperitoneum on imaging (11 cases, 17.46\%). The other $17(21.25 \%)$ were operated secondarily after failure of an initial conservative attitude. The reason of the failure of the conservative treatment were appearance of signs of peritoneal irritation in 11 cases (due to lesions of the hollow viscera not noticed at initial assessment or secondary to intestinal necrosis) and a secondary alteration in hemodynamic status in 6 cases. Spleen and jejunum/ileum were the most injured viscera after abdominal contusions in $66.25 \%$ and $17.5 \%$ of patients respectively. Figure 2 shows the organs injured after abdominal contusions. Splenectomy was the most performed surgical procedure in $61.25 \%$. The operative findings and the procedures performed are summarized in Table 2. The postoperative morbidity was 7.5\% (6 patients) represented by three cases of surgical site infection, two cases of postoperative peritonitis and one case of digestive fistula. The evolution was favourable for five of them. The sixth who presented a septic shock following postoperative peritonitis after a colonic wound passed away. Two other patients died giving a mortality of $3.75 \%$ (3 patients). One of them had haemorrhagic shock after liver injury and died during surgery. The second had a duodenal wound in a context of polytrauma and died few hours after the surgery. 
Table 2. Operative findings and procedures performed in abdominal contusions.

\begin{tabular}{|c|c|c|c|}
\hline Findings & Procedures & Number & Percentage \\
\hline \multirow[t]{2}{*}{ Spleen rupture } & Splenectomy & 49 & 61.25 \\
\hline & Spleen suture & 4 & 5 \\
\hline \multirow[t]{2}{*}{ Liver injury } & Tamponade & 6 & 7.5 \\
\hline & No gesture & 2 & 2.5 \\
\hline Gastric perforation & Suture + omental patch & 2 & 2.5 \\
\hline \multirow[t]{2}{*}{ Duodenal wound } & Simple suture & 1 & 1.25 \\
\hline & Duodéno-jejunostomy & 1 & 1.25 \\
\hline \multirow[t]{2}{*}{ Small bowel perforation } & Simple suture & 5 & 6.25 \\
\hline & Resection + anastomosis & 9 & 11.25 \\
\hline \multirow[t]{2}{*}{ Colonic wound } & Simple suture & 1 & 1.25 \\
\hline & Resection + anastomosis & 2 & 2.5 \\
\hline \multirow[t]{2}{*}{ Mesentery rupture } & Suture of the breach & 2 & 2.5 \\
\hline & Small bowel resection + anastomosis & 1 & 1.25 \\
\hline
\end{tabular}

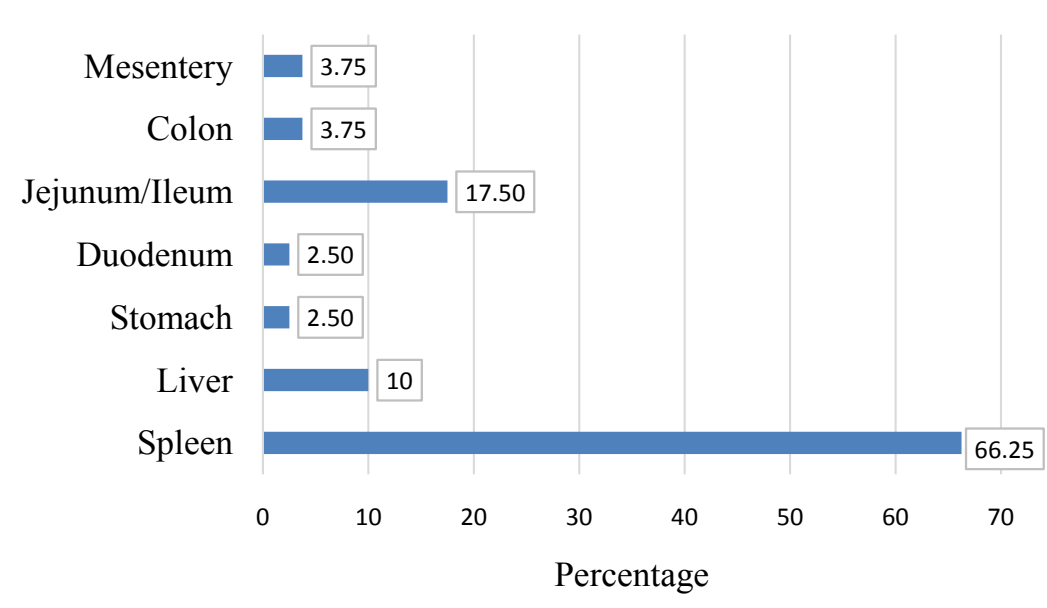

Figure 2. Organs injured after abdominal contusions.

In the abdominal wounds group ( $\mathrm{n}=35)$, the aetiology was an assault in 33 cases $(94.28 \%)$. A bladed weapon was involved in $78.8 \%$ of cases and a firearm in $21.2 \%$ of cases. Hemodynamic instability was present in $22.85 \%$ of patients. Signs of peritoneal irritation were found in $68.57 \%$ of cases. Flow of digestive fluid through the orifice was noted in two patients (5.71\%). The surgical indication was made from the outset in 29 patients $(82.85 \%)$ because of: refractory hemodynamic instability (6 cases, $17.14 \%$ ), peritonitis (22 cases, $62.85 \%$ ) and evisceration of the small intestine (3 cases, $8.57 \%$ ). Patients with gunshot wounds (20\%) had a mandatory laparotomy in all cases. Six patients (17.14\%) who initially presented with evisceration of the omentum without any other associated clinical sign and managed conservatively by toilet and reintegration under local anaesthesia, developed peritonitis secondarily, justifying a laparotomy. Jejunum/ileum perforation was the most frequent lesion encountered in $62.85 \%$ of patients. Abdominal wound with evisceration was present in $25.71 \%$ of cases. The organs injured after abdominal wounds are reported in Figure 3. Simple suture was the main performed procedure for hallow viscera injuries. The operative findings and procedures performed are summarized in Table 3. In four cases 
Table 3. Operative findings and procedures performed in abdominal wounds.

\begin{tabular}{llcc}
\hline \multicolumn{1}{c}{ Findings } & \multicolumn{1}{c}{ Procedures } & Number & Percentage \\
\hline Liver injury & Tamponade & 3 & 8.57 \\
& Suture & 1 & 2.85 \\
Gastric perforation & Suture + omental patch & 5 & 14.28 \\
Duodenal wound & Simple suture & 1 & 2.85 \\
Small bowel evisceration & Toilet + reinstatement & 1 & 2.85 \\
(without perforation) & & & 40 \\
Small bowel perforation & Simple suture & 14 & 22.85 \\
(including 2 cases of evisceration) & Resection + anastomosis & 8 & 2.85 \\
Colonic wound & Simple suture & 1 & 2.85 \\
& Resection + anastomosis & 1 & 5.71 \\
Mesentery rupture & Suture/resection + stoma & 2 & 8.57 \\
\hline
\end{tabular}

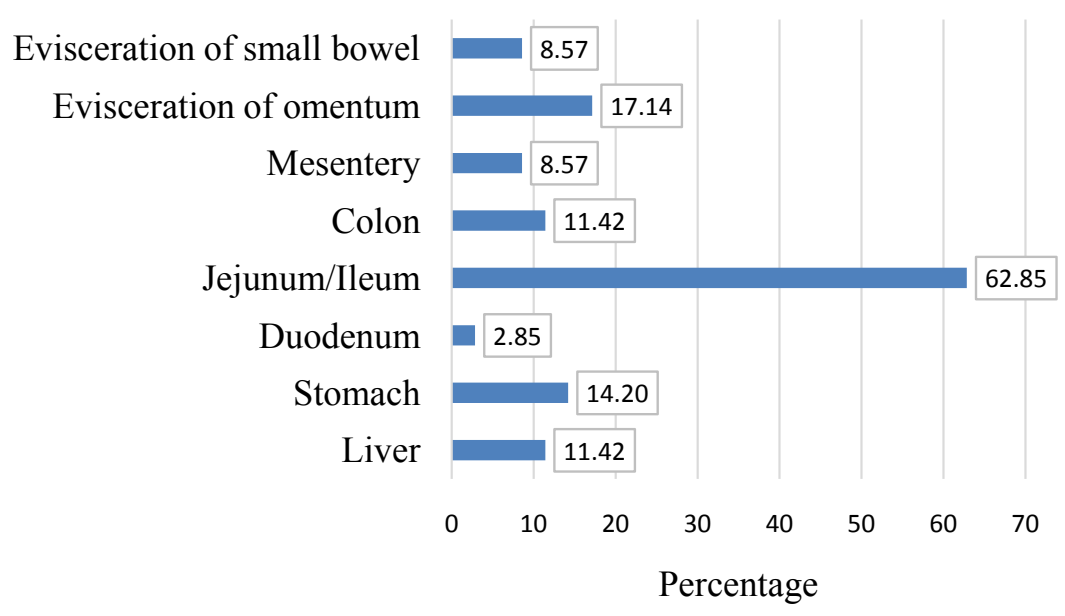

Figure 3. Organs injured after abdominal wounds.

(11.42\%), the laparotomy was non-therapeutic. Five cases of postoperative complications were recorded, leading to a morbidity rate of $14.28 \%$; two of them consisted of surgical site infection, two of enterocutaneaous fistula and 1 case of septic shock following a colonic gunshot wound. One case of death was recorded (2.85\%) related to a septic shock.

\section{Discussion}

AT remains a major public health problem. They occupy an important place in the activities of emergency services. They accounted for $55.4 \%$ of all trauma in our series and more than half (54.6\%) were operated. They are responsible for an often-high mortality [1] [2]. In the face of an AT, the action to be taken is dictated by the type and extent of the associated visceral lesions. If in abdominal contusions, the indications for surgery are fairly codified, the attitude is less consensual in penetrating wounds. In this study, we were interested in the indications and results of laparotomies for AT. To achieve these objectives, we collected 115 AT including 80 abdominal contusions (69.6\%) and 35 penetrating wounds of the abdomen (30.4\%). The predominance of abdominal contusions is 
reported in several studies [1] [2] [3] [4] [11] [12]. The weaknesses of this work lie in the retrospective data collection with all the limitations inherent in this type of data collection. Thus, 91 of the 206 files of patients operated on after AT could not be used, for an exclusion rate of $44.17 \%$. However, the multicentre character is a strength of this work.

The aetiologies of AT are multifactorial. However, RTA are the first cause in our series as well as in many others [3] [4] [5] [6]. The high number of twowheeled motorized vehicles used as means of transport by many road users is one explanation for this high proportion of RTA. If this is verified in abdominal contusions, penetrating wounds of the abdomen are often secondary to assaults with stabbing or firearms as injurious objects in the context of homicides or attempted autolysis [3] [8] [13] [14]. Assault with a knife (74.3\%) and firearm (20\%) was found in $38.3 \%$ of AT and $94.3 \%$ of penetrating wounds of the abdomen in our series. The increase in delinquency and organized crime observed here and elsewhere could explain these figures. We noted a male predominance (sex ratio of 5.1) as reported in most publications [3] [4] [5] [6] [8] [12] [13] [14] [15]. As in many series [3] [4] [5] [6] [8] [12] [13] [14] [15], our population was essentially young $(33.8 \pm 11.3$ years old and $82.6 \%$ of patients under 45 years old). The young age of the subjects could be explained by the fact that trauma most often occurs in active people with an increasing participation of young people in socio-economic activities.

Admission delay (12.3 hours \pm 11.7$)$ in our series as in several other African studies is long [2] [3] [4] [5] [6] [12] [16]. In two Burkinabe and Beninese series, nearly one in four patients consulted after the 24 th hour, $22.2 \%$ and $24.36 \%$ respectively [4] [12]. The lack of a well-structured and functional emergency medical aid service in most African countries and in ours, could explain these long admission delays. Indeed, the majority of our patients is taken to emergency departments by non-medical means, most often in personal or transport vehicles [2] [3] [15] [16] [17].

The management of AT remains a real challenge for practitioners. Abdominal contusions are a diagnostic and therapeutic challenge in our context. As opposed to penetrating wounds of the abdomen, abdominal contusions have a higher induced mortality rate because they are difficult to diagnose and are often associated with other extra-peritoneal injuries related to the mechanism most often involved [2] [3] [16] [18] [19] [20] [21]. In this context, recourse to morphological examinations is most often necessary. In our study, only few imaging examinations were performed. A CT scan was only obtained in $17.4 \%$ of our patients. Authors from the continent have used imaging very infrequently in the initial assessment of these patients [2] [4] [5] [6] [12] [15] [17]. While morphological examinations are not always possible in patients with refractory shock, the difficulties associated with their cost and their availability in a context of emergency limit their access to us. The treatment decision is based on the hemodynamic state and the search for a lesion of a hollow viscus. Emergency surgery should be performed in patients with unstable abdominal trauma despite 
well-conducted resuscitation, or in case of obvious hollow organ damage [18] [19] [20]. This is how the surgical indication was made immediately in 63 (78.75\%) of our patients with abdominal contusion, faced with refractory hemodynamic instability ( 42 cases, $66.67 \%$ ), peritonitis (17 cases, $27 \%$ ), pneumoperitoneum on imaging (11 cases, 17.46\%). In the absence of these elements, non-operative treatment is the rule [2] [3] [16] [18] [19] [20] [21]. However, this attitude requires armed surveillance by a multidisciplinary team involving surgeons, resuscitators and radiologists. This is justified by the high frequency of secondary laparotomies due to attitude failure, which can reach $32.4 \%$ [16]. Seventeen (21.25\%) of our patients were operated secondary after failure of initial conservative treatment.

The management of penetrating abdominal wounds remains a matter of controversy. If surgery is the rule after a gunshot wound, it is also performed urgently, for many authors, after a stab wound, in case of refractory haemorrhagic shock, evidence of lesion of hollow viscera or evisceration [8] [13] [14]. Thus, in $29(82.85 \%)$ of our operated patients, the indication for surgery was made from the outset after the initial assessment. The other six patients (17.15\%) were operated secondarily after failure of a conservative attitude indicated for an isolated evisceration of the omentum without any other obvious digestive lesion. If the rupture of the parietal peritoneum is an indication for systematic exploratory laparotomy for some authors [1] [5] [12] [22], a non-operative attitude for patients with penetrating abdominal wound without obvious digestive involvement with or without omental evisceration is proposed by several recent studies [23] [24]. Routine laparotomy has the advantage of a comprehensive assessment of intra-abdominal lesions that may have gone unnoticed during the initial assessment. However, it is responsible for a high rate of non-therapeutic laparotomies [5] [8] [13] [25] [26] [27], which can be around 50\% in asymptomatic patients [5]. According to Ramya et al., simple peritoneal penetration is a poor indicator of emergency laparotomy in abdominal stab wound [22]. In the other hand, selective attitude is sanctioned by a significant rate of secondary interventions, although lower than the rate of non-therapeutic laparotomies after systematic surgery, with an overlapping morbidity and mortality [8] [27] [28]. It should therefore be reserved for carefully selected patients.

The average length of hospitalization was 9.7 days \pm 12.3 , approaching that of our African colleagues [3] [16] [17] [18] [19] [20] [25]. In a series published in 2020 in the Democratic Republic of Congo, an average hospital stay of 16.1 days was reported, probably linked to the high frequency of associated extra-abdominal lesions, found in $91.9 \%$ of patients [2]. We found a morbidity of $9.6 \%$ and a mortality of 3.5\% closed to those found in the African literature [3] [6] [12] [15] [16] [17]. Surgical site infections are the main complications present in these author's series and in ours. In their series with a high proportion of associated extra-abdominal lesions, Saleh Ugumba et al. reported high morbidity and mortality of $37.83 \%$ and $27.02 \%$ respectively [2]. 


\section{Conclusion}

Laparotomy for AT is a frequent procedure in our practice. The indications are hemodynamic instability, evidence of a lesion of a hollow viscus, the presence of evisceration or a gunshot wound, and the failure of an initial conservative attitude. A good selection of patients leads to a low rate of non-therapeutic laparotomies as in our study with a mobi-mortality comparable to that of the other series.

\section{Authors' Contribution}

EPS conceited the study. GAB and DBB collected the data, which were analyzed by LJBAM, GRBM and MYEB. EPS and GAB wrote the paper. BNN revised and edited the work. AE gave the final approval.

\section{Conflicts of Interest}

The authors declare no conflicts of interest regarding the publication of this paper.

\section{References}

[1] Gad, M.A., Saber, A., Farrag, S., Shams, M.E. and Ellabban, G.M. (2012) Incidence, Patterns, and Factors Predicting Mortality of Abdominal Injuries in Trauma Patients. North American Journal of Medical Sciences, 4, 129-134. https://doi.org/10.4103/1947-2714.93889

[2] Saleh Ugumba, C., Kibonge Mukakala, A., Mukimba Ngambunda, P., Kaoma Cabala, V.D.P. and Mbuya Musapud, E. (2020) Epidemiological, Clinical and Therapeutic Aspects of Post-Traumatic Hemoperitoines Operated at Jason Sendwe Hospital in Lubumbashi. The Journal of Medical Research, 6, 166-171. https://doi.org/10.31254/jmr.2020.6413

[3] Ndong, A., Sarr, I.S.S., Gueye, M.L., Seye, Y., Diallo, A.Y., Thiam, O., et al. (2018) Aspects diagnostiques et thérapeutiques des traumatismes abdominaux: À propos 68 cas. Journal Africain de Chirurgie Digestive, 18, 2474-2478.

[4] Belemlilga, G.L.H., Zaré, C., Yabré, N., Keita, N., Benao, B.L., Somé, O.R., et al. (2020) Traumatismes de L'abdomen en Milieu Africain: Aspects Épidémiologiques, Diagnostiques, et Thérapeutiques. European Scientific Journal, 16, 132-141. https://doi.org/10.19044/esj.2020.v16n21p132

[5] Raherinantenaina, F., Rakotomena, S.D., Rajaonarivony, T., Rabetsiahiny, L.F., Rajaonanahary, T.M.N.A., Rakototiana, F.A., et al. (2015) Traumatismes fermés et pénétrants de l'abdomen: Analyse rétrospective sur 175 cas et revue de la littérature. The Pan African Medical Journal, 20, Article ID: 129.

[6] Hama, Y., Kadi, I., Garba, I., Sani, R. and Harouna, Y.D. (2019) Morbi-Mortalité des Contusions Abdominales: La Face Visible de L'iceberg. European Scientific Journal, 15, 125-132.

[7] Traoré, A., Diakite, I., Togo, A., Dembélé, B., Kante, L., Maiga, A.I., et al. (2010) Hémopéritoine non opératoire dans les traumatismes fermés de l'abdomen (CHU Gabriel-Touré). Journal Africain d’ Hépato-Gastroentérologie, 4, 225-229.

[8] Dieng, M., Wilson, E., Konaté, I., Ngom, G., Ndiaye, A., Ndoye, J.M., et al. (2003) Plaies pénétrantes de l'abdomen: "Abstentionnisme sélectif" versus laparotomie 
systématique. E-Mémoires de 1 Académie Nationale de Chirurgie, 2, 22-25.

[9] Wilson, R.H. and Moorehead, R.J. (1991) Current Management of Trauma of the Pancreas. British Journal of Surgery, 78, 1196-1202. https://doi.org/10.1002/bjs.1800781017

[10] Smit, S.J.A. and Kleinhans, F. (2010) Surgical Practice in a Maximum Security Prison-Unique and Perplexing Problems. The South African Medical Journal, 100, 243-246. https://doi.org/10.7196/SAMJ.3727

[11] Walia, B.S., Kapur, V., Nyitan, T., Kiranjot, Singh, R. and Neki, N.S. (2017) Clinical Profile and Aids to Diagnosis and Management of Trauma Abdomen. International Journal of Current Research in Medical Sciences, 3, 14-20. http://dx.doi.org/10.22192/ijcrms.2017.03.05.004

[12] Tamou Sambo, B., Montcho Hodonou, A., Salako Allode, A., Mensah, E., Youssouf, M. and Menhinto, D. (2016) Aspects épidémiologiques, diagnostiques et thérapeutiques des traumatismes abdominaux à Bembéréké-Nord Bénin. European Scientific Journal, 12, 395-405. https://doi.org/10.19044/esj.2016.v12n9p395

[13] Bombah, F., Biwolé, D., Ekani, B., Ngo Nonga, B. and Essomba, A. (2020) Prise en Charge Chirurgicale des Plaies Pénétrantes Abdominales à l'Hôpital Laquintinie de Douala: Indications, Techniques et Résultats. Health Sciences and Diseases, 21, 55-61.

[14] Kendja, K.F., Kouame, K.M., Coulibaly, A., Kouadio, K., Koffi Konan, B., Sissoko, M., et al. (1993) Traumatisme de l'abdomen au cours des agressions à propos de 192 cas. Médecine d Afrique Noire, 40, 567-575.

[15] Choua, O., Rimtebaye, K., Adam Adami, M., Bekoutou, G. and Anour, M.A. (2016) Les plaies pénétrantes par armes blanches et à feu à N'djamena, Tchad: Une épidémie silencieuse? European Scientific Journal, 12, 180-191.

https://doi.org/10.19044/esj.2016.v12n9p180

[16] Ndong, A., Gueye, M.L., Thiam, O., Sow, O., Diop, A., Sarr, I.S.S., et al. (2020) Epidemiological and Clinical Profile of Patients with Blunt Abdominal Trauma at Aristide Le Dantec Hospital of Dakar. Open Journal of Surgery, 4, 1-4.

[17] Choua, O., Rimtebaye, K., Yamingue, N., Moussa, K. and Kaboro, M. (2017) Aspects des traumatismes fermés de l'abdomen opérés à l'Hôpital Général de Référence Nationale de N'Djaména (HGRN), Tchad: À propos de 49 cas. The Pan African Medical Journal, 26, Article ID: 50.

[18] Tchangai, B.K., Gayito, A., Alassani, F., Dosseh, E.D. and Attipou, K. (2017) Criteres du traitement non opératoire des contusions abdominales en milieu sous équipé. European Scientific Journal, 13, 358-367. https://doi.org/10.19044/esj.2017.v13n21p358

[19] Rabbani, K., Narjis, Y., Louzi, A., Benelkhaiat, R. and Finech, B. (2015) La place du traitement non opératoire des contusions abdominales dans les pays en voie de développement. The Pan African Medical Journal, 20, Article ID: 132.

[20] Raza, M., Abbas, Y., Devi, V., Prasad, K.V.S., Rizk, K.N. and Nair, P.P. (2013) Non operative Management of Abdominal Trauma-A 10 Years Review. World Journal of Emergency Surgery, 8, Article No. 14. http://www.wjes.org/content/8/1/14 https://doi.org/10.1186/1749-7922-8-14

[21] Rajkumar, P.N., Kushal Kumar, T.R. and Deepak, G. (2018) Challenges in Management of Blunt Abdominal Trauma: A Prospective Study. International Surgery Journal, 5, 3298-3304. https://doi.org/10.18203/2349-2902.isj20184078

[22] Ramya, C. and Jayasree, K. (2017) A Profile of 96 Cases of Penetrating Injury of Abdomen. International Journal of Research in Medical Sciences, 5, 2993-2997. 
https://doi.org/10.18203/2320-6012.ijrms20172975

[23] da Silva, M., Navsaria, P.H., Edu, S. and Nicol, A.J. (2009) Evisceration Following Abdominal Stab Wounds: Analysis of 66 Cases. World Journal Surgery, 33, Article No. 215. https://doi.org/10.1007/s00268-008-9819-y

[24] Clarke, S.C., Stearns, A.T., Payne, C. and McKay, A.J. (2008) The Impact of Published Recommendations on the Management of Penetrating Abdominal Injury. British Journal of Surgery, 95, 515-521. https://doi.org/10.1002/bjs.5995

[25] Guiberteau, B., Koen, M., Borde, L., Sartre, J.Y., Bourseau, J.C. and Le Neel, J.C. (1992) Le dogme de la laparotomie exploratrice doit-il être maintenu en présence d'une plaie de l'abdomen? Discussion à propos de 176 observations. Journal de Chirurgie, 129, 420-425.

[26] Ayite, A., Etey, K., Fekete, L., Dossin, M., Tchatagba, K., Senah, K., et al. (1996) Les plaies pénétrantes de l'abdomen au CHU de Lomé à propos de 44 cas. Médecine d Afrique Noire, 43, 642-646.

[27] El Idrissi, H.D., Kafih, M., Ajbal, M., Ridai, M., Sarf, I., Salmi, A., et al. (1994) Les plaies pénétrantes de l'abdomen. Résultats des deux attitudes classique et sélective dans la prise en charge de 249 plaies. Journal de Chirurgie, 131, 375-377.

[28] Masso-Misse, P., Essomba, A., Kim, S.W., Fowo, S., Afane Ela, A., Gonsu, J.D., et al. (1996) Plaies pénétrantes asymptomatiques de l'abdomen par arme blanche: Pour une exploration sélective. Médecine d' Afrique Noire, 43, 83-85. 